\title{
Conhecimentos mobilizados em contexto colaborativo acerca da generalização algébrica nos anos iniciais
}

\author{
Knowledge mobilized in collaborative context about algebric generalization in the early \\ years
}

\author{
Silvana Leonora Lehmkuhl Teres ${ }^{1}$ \\ Regina Célia Grando ${ }^{2}$
}

\begin{abstract}
Resumo
Neste artigo discutimos os conhecimentos profissionais docentes do Professor que Ensina Matemática para o desenvolvimento do pensamento algébrico nos anos iniciais, sobretudo relativos à generalização de padrões em sequências recursivas, que foram mobilizados por professoras-pesquisadoras em um grupo de estudos reconhecido pelos integrantes como colaborativo. Este artigo é parte de uma pesquisa qualitativa longitudinal desenvolvida em nível de doutorado com característica de pesquisa-formação. As discussões e análises foram pautadas na Pesquisa narrativa e sinalizam que este espaço de formação oportunizou uma dinâmica que favoreceu a interação e a comunicação matemática entre Futuros Professores, Professores da Universidade e Professores que Ensinam Matemática em diferentes segmentos da Educação Básica; a ressignificação da ideia de generalização de padrões em sequências recursivas articulada às questões da profissão docente e à reflexão sobre a própria prática dos participantes.
\end{abstract}

Palavras-chave: Desenvolvimento Profissional Docente; Conhecimento Matemático para o Ensino (MTK); Desenvolvimento do pensamento algébrico.

\begin{abstract}
In this article, we discuss the professional teaching knowledge of the teachers who Teaches Mathematics for the development of algebraic thinking in the early years, especially regarding the generalization of patterns in recursive sequences, which were mobilized by professors-researchers in a study group recognized by its members as collaborative. This article is part of qualitative longitudinal research developed at the doctoral level with a research-formation characteristic. Discussions and analyzes were based on narrative research and indicate that this training context provided a dynamic that favored interaction and mathematical communication between Future Teachers, Professors, and Teachers who Teach Mathematics in different segments of Basic Education; the resignification of the idea of a generalization of patterns in recursive sequences articulated to the issues of the teaching profession and the reflection on the participants' own practice.
\end{abstract}

Keywords: Teacher Professional Development; Mathematical Knowledge for Teaching; Development of algebraic thinking.

Submetido em: 29/10/2020 - Aceito em: 30/11/2021 - Publicado em: 31/12/2021

${ }^{1}$ Doutora em Educação Científica e Tecnológica (PPGECT)/UFSC. Professora de Matemática do Colégio de Aplicação da Universidade Federal de Santa Catarina (UFSC). E-mail: silvanaeleonorateres@gmail.com. ORCID: https://orcid.org/0000-0002-8073-835X

2 Doutora em Educação pela UNICAMP. Professora Titular do Centro de Ciências da Educação, Departamento de Metodologia de Ensino e docente do Programa de Pós-graduação em Educação Científica e Tecnológica da Universidade Federal de Santa Catarina (UFSC). E-mail: regrando@yahoo.com.br. ORCID: https://orcid.org/0000-0002-2775-0819 


\section{Introdução}

Para atender as demandas que emergem na sociedade atual faz-se necessário uma concepção de formação de professores fundamentada na reflexão crítica diante dos diferentes saberes que estão em contínua evolução. E, o reconhecimento de que além dos conhecimentos para o ensino da disciplina (Shulman, 1986) há a necessidade de maior aprofundamento pelos professores das questões acerca da sua profissão docente. Essa perspectiva de formação de professores denominada por desenvolvimento profissional docente é compreendida como um processo de aprendizagem contínuo que parte de questionamentos da prática pedagógica, o que contribui para gerar mudança no modo de pensar e de agir dos professores, pois para além da reflexão individual, a reflexão do professor também é concebida como uma prática social (Garcia, 1999; Imbernón, 2010; Nóvoa, 2008; Zeichner, 2010; Rodrigues, Cyrino \& Oliveira, 2018). Contrapondo-se às concepções de formação de professores mais formalistas, pautadas na racionalidade técnica ${ }^{3}$, a perspectiva de desenvolvimento profissional docente reconhece o professor como protagonista do seu próprio processo formativo, sendo assim, ele mesmo busca os conhecimentos que fazem sentido e trazem significado para a sua ação docente e aprendizagem profissional (Fiorentini \& Crecci, 2013).

No campo da formação do Professor que Ensina Matemática, há uma tendência de investigações que consideram aspectos relacionados ao desenvolvimento profissional desses professores, como as suas práticas profissionais, conhecimentos docentes, identidade profissional, trajetória, crenças e concepções. Do mesmo modo emergem estudos acerca de contextos formativos híbridos, que oportunizam a troca de conhecimentos entre Futuros Professores, Formadores de Professores e Professores em exercício, a aproximação entre os referenciais acadêmicos e as práticas materializadas nas escolas e podem contribuir para à constituição conhecimentos e a ressignificação de crenças e concepções dos professores que ensinam matemática (Fiorentini, Passos \& Lima, 2016). Os grupos de estudos colaborativos podem ser caracterizados como contextos de formação híbridos e alternativos para a busca de soluções ou a compreensão das situações que emergem nas dicotomias entre formação inicial e formação continuada, teoria e prática, saberes acadêmicos e escolares, entre outras. Esses aspectos foram sinalizados nos estudos de Fiorentini (2019) sobre o trabalho colaborativo entre professores iniciantes e experientes. Para esse autor, ao participarem colaborativamente de trabalhos intelectuais comuns, professores iniciantes e experientes, levantam problemas, identificam discrepâncias entre teorias e práticas, desafiam rotinas, apoiam-se mutuamente na construção de conhecimentos que tornem visíveis, o que é considerado implícito no processo de ensino e aprendizagem nas aulas de matemática (Fiorentini, 2019).

Estudos evidenciam que o conhecimento do professor é relevante para as aprendizagens dos estudantes e que a sua formação inicial e contínua é significativa para o

\footnotetext{
${ }^{3}$ É uma concepção de formação de professores que não considera os conhecimentos docentes voltados à experiência profissional dos professores, portanto considera que eles devem assumir uma postura passiva em relação às escolhas relacionadas sobre suas aprendizagens.
} 
aprimoramento das suas aprendizagens (Shulman, 1986; Fiorentini, 2003). No âmbito da Educação Matemática, estudos acerca do conhecimento profissional docente defendem que o conhecimento mobilizado pelo Professor que Ensina Matemática em suas ações voltadas para o ensino caracteriza a especificidade desse profissional. E que esse conhecimento especializado, pode ser explicitado no modo como o Professor que Ensina Matemática elabora, desenvolve e analisa as tarefas que propõe aos estudantes (Ball et al., 2008; Carrillo et al., 2013; Ribeiro, 2017). Para tanto, faz-se necessário que os espaços formativos dos Professores que Ensinam Matemática propiciem discussões que possibilitem a articulação entre os referenciais teóricos, epistemológicos e pedagógicos dos conteúdos matemáticos trabalhados na Educação Básica, e oportunizem interações sociais, a comunicação matemática e trocas de experiências entre os participantes para que o conhecimento especializado desses professores seja mobilizado e desenvolvido (Trivilin \& Ribeiro, 2015).

Defendemos que o Professor que Ensina Matemática precisa vivenciar ao longo do seu processo formativo experiências que favoreçam a discussão dos diversos conhecimentos voltados ao ensino dos conteúdos matemáticos, a reflexão crítica acerca das questões que envolvem a sua profissão docente e a sua própria prática pedagógica. Todavia, neste artigo damos enfoque aos conhecimentos a para o ensino do conteúdo matemático, em especial, ao desenvolvimento da ideia de generalização de padrões em sequências recursivas. As informações trazidas nas discussões são oriundas de um estudo qualitativo e longitutinal, a nível de doutorado, desenvolvido em um grupo de estudos e pesquisas reconhecido por seus integrantes como colaborativo, denominado por ICEM - Insubordinações Criativas em Educação Matemática vinculado à Universidade Federal de Santa Catarina.

Associado à compreensão e à conexão de diferentes ideias matemáticas, o pensamento algébrico, quando explorado adequadamente nas ações de generalizar, abstrair e formalizar repercute transversalmente na aprendizagem da matemática e das demais áreas de conhecimento. Para isso, é preciso que os espaços de formação o considerem como um modo distinto de ver e agir matematicamente que apoia a compreensão de outros conceitos e favorece o aprofundamento das capacidades cognitivas e linguísticas das crianças (Boavida et al., 2008; Canavarro, 2009).

Partimos da seguinte questão investigativa: Como as ações desenvolvidas pelos professores nos momentos de estudo em um grupo colaborativo mobilizam os conhecimentos para o desenvolvimento do pensamento algébrico nos anos iniciais? Considerando a limitação de espaço escolhemos para este artigo trazer a discussão dos professores participantes do ICEM no estudo de um dos textos escolhidos pelo grupo para subsidiar as discussões acerca da generalização de padrões em sequências recursivas com o uso de tarefas exploratórias. As informações trazidas foram norteadas pelos aportes da Pesquisa Narrativa, de acordo com Clandinin e Connelly, (2011) por compreendermos que seus pressupostos estão alinhados à abordagem qualitativa, aos estudos longitudinais e aos da pesquisa da própria prática.

As discussões sobre os conhecimentos mobilizados para o ensino do conteúdo matemático foram pautadas no modelo proposto por Ball et al. (2008) do Conhecimento 
Matemático para o Ensino, reorganizado a partir dos conhecimentos que constituem a base para o ensino (Shulman, 1986). A opção por esse referencial está atrelada às pesquisas desses autores acerca dos conhecimentos mobilizados pelos professores em e para o ensino, essa preocupação em compreender esses conhecimentos no fazer pedagógico transcende à concepção da preponderância do conhecimento acadêmico de uma determinada área para o ensino da disciplina dessa área na Educação Básica e está alinhada aos pressupostos que fundamentam as ações dos integrantes do grupo ICEM.

Pretendemos com esse artigo compartilhar nossa vivência e contribuir para fomentar discussões acerca do desenvolvimento do pensamento algébrico dos estudantes dos anos iniciais e do Conhecimento Especializado do Conteúdo Matemático Ball et al. (2008), em especial no que se refere à generalização em sequências recursivas.

\section{Conhecimentos para ensinar matemática}

De acordo com Shulman (1986), os professores precisam demonstrar na ação docente um conjunto de compreensões, habilidades, conhecimentos e motivações necessários ao ofício de ensinar. Esse conhecimento do professor para ensinar deriva de um conjunto de conhecimentos adquiridos durante a trajetória acadêmica, profissional e pessoal, aos quais ele denomina de base de conhecimento para o ensino 4 . Para o autor, esses conhecimentos propiciam o reconhecimento da especificidade da prática docente e possuem aspectos intrínsecos que o constituem pela inter-relação dos conhecimentos da área específica e os conhecimentos pedagógicos para ensiná-los. Tais saberes são possíveis de serem identificados, embora difíceis de serem explicados e teorizados pelos próprios professores. Para Shulman (1986) esses conhecimentos de conteúdos de diferentes naturezas podem ser reunidos em três categorias de conhecimentos, às quais denominou por Conhecimento Específico do Conteúdo, Conhecimento Pedagógico do Conteúdo e o Conhecimento Curricular do Conteúdo.

O modelo proposto por Shulman (1986) refere-se, de modo geral, ao conhecimento necessário para ensinar, porém sem focalizar uma determinada área. Na perspectiva da área da Educação Matemática, Ball et al. (2008) desenvolveram o modelo Mathematical Knowledge for Teaching (MKT), que propõe uma reorganização dos conhecimentos categorizados por Shulman, na perspectiva do Conhecimento Matemático para o Ensino. Assim, a partir da abordagem de Shulman (1986), dividiram os conhecimentos para o ensino da matemática em dois domínios: o domínio do Conhecimento do Conteúdo (CK) e o domínio do Conhecimento Pedagógico do Conteúdo (PCK). No domínio do Conhecimento do Conteúdo (CK), encontram-se três subdomínios. O subdomínio do Conhecimento do Conteúdo no Horizonte $(\mathrm{HCK})^{5}$, que não é utilizado diretamente para ensinar os conteúdos no nível em que o professor irá lecionar, corresponde a um conhecimento mais avançado da disciplina, entretanto sustenta e apoia o professor nas mediações e contrapontos que

\footnotetext{
${ }^{4}$ knowledge base for teaching

${ }^{5}$ Horizon Content Knowledge.
} 
considera importantes para enfatizar o que é relevante matematicamente e ampliar as conexões acerca do conteúdo ao qual está ensinando. Os outros dois subdomínios do domínio do Conhecimento do Conteúdo (CK) podem ser mais facilmente percebidos na ação docente. O Conhecimento Comum do Conteúdo $(\mathrm{CCK})^{6}$ que está relacionado ao "saber fazer", também é utilizado em outros contextos por diferentes profissionais, como por exemplo, o conhecimento matemático que um engenheiro utiliza para calcular a carga que irá suportar uma viga de concreto. E o subdomínio do Conhecimento Especializado do Conteúdo (SCK) ${ }^{7}$, que segundo os autores, é próprio do professor, ao exercer a ação de ensinar os conteúdos matemáticos, e pode ser percebido na ação de ensino desse profissional ao trazer diferentes representações de um conceito matemático, ou pela compreensão das propriedades que sustentam um determinado procedimento de resolução. Esse conhecimento está associado ao conhecimento que atribui sentido e procura interpretar às estratégias de resolução dos estudantes, em especial, aquelas discutidas na sua classe ou previstas em seu planejamento. Assim, ao Conhecimento Especializado do Conteúdo (SCK) está associada à compreensão das possíveis causas que originam as estratégias de resolução incorretas dos estudantes, ou seja, a interpretação da natureza dos erros nas respostas dos estudantes, esse conhecimento é denominado por Conhecimento Interpretativo (IK).

No domínio do Conhecimento Pedagógico do Conteúdo (PCK), do modelo do (MKT), também foram alocados três subdomínios. O subdomínio do Conhecimento do Conteúdo e dos Estudantes $(\mathrm{KCS})^{8}$, associado à identificação das dificuldades para a aprendizagem do conteúdo a ser ensinado, sinalizadas em outras turmas do mesmo nível de ensino e que podem auxiliar o professor a antecipar os aspectos que precisam de maior atenção e para fazer mediações que mobilizarão a aprendizagem desse conteúdo. $\mathrm{O}$ subdomínio do Conhecimento do Conteúdo e do Ensino (KCT) ${ }^{9}$ refere-se aos conhecimentos que o professor mobiliza para planejar a sua abordagem pedagógica, fazer escolhas dos materiais que irão apoiar suas explicações e as tarefas que irá propor aos estudantes. E ao Conhecimento do Conteúdo e do Currículo $(\mathrm{KCC})^{10}$, está relacionado ao reconhecimento pelo professor da distribuição dos objetos matemáticos e suas conexões no currículo da disciplina de matemática de acordo com os documentos oficiais e os objetivos de aprendizagem desses conteúdos para cada ano ao longo da Educação Básica. Esse conhecimento permite ao professor fazer antecipações ou relações do conteúdo que está ensinando com ideias, propriedades ou conceitos abordados em anos anteriores ou posteriores pelos estudantes da sua classe.

De acordo com o que propõe Ball et al. (2008) compreendemos que, em relação aos conteúdos do pensamento algébrico dos anos iniciais, o Conhecimento Comum do Conteúdo

\footnotetext{
${ }^{6}$ Common Content Knowledge.

${ }^{7}$ Specialized Content Knowledge.

${ }^{8}$ Knowledge Content and students.

${ }^{9}$ Knowledge Content and teaching.

${ }^{10}$ Knowledge Content and curriculum.
} 
(CCK) matemático, está relacionado à compreensão dos conceitos e ao reconhecimento dos processos que desenvolvem a ideia de generalização em sequências repetitivas e recursivas e ao processo resolutivo das expressões aritméticas, e ao Conhecimento Especializado do Conteúdo (SCK) está a preocupação de compreender o porquê se utiliza determinada propriedade ou não, e de como explicar essa compreensão para os estudantes, para que eles entendam os conceitos e façam conexões com outras ideias já consolidadas. Essa compreensão, é importante para o professor fazer escolhas acerca das antecipações e conceitos que considera necessários para o reconhecimento do motivo e a identificação de termos distantes de sequências repetitivas; reconhecer a parte que varia ou é invariante de termos próximos e identificar a lei de formação de sequências recursivas, e escolher a abordagem e os recursos que irá utilizar com o intuito de promover da aprendizagem desses objetos matemáticos pelos estudantes, e estão associados ao Conhecimento do Conteúdo e do Ensino (KCT). Ao Conhecimento do Conteúdo e dos Estudantes (KCS), estão contemplados os conhecimentos das prováveis estratégias de resolução que podem ser utilizadas pelos estudantes da classe em que leciona, como, os possíveis obstáculos que eventualmente, podem emergir para a compreensão desses objetos com o uso de tarefas exploratórias com estudantes que se encontram em classes que estão próximas ou no mesmo ano de escolaridade. E ao Conhecimento do Conteúdo e do Currículo (KCC), está associado o reconhecimento pelo professor da concepção da BNCC (Brasil, 2017), para o trabalho dos conteúdos do eixo Álgebra nos anos iniciais, às orientações para desenvolver a ideia de generalização nesse segmento e a distribuição dos conteúdos do Eixo Álgebra ao longo da Educação Básica.

Dentre as abordagens associadas ao Conhecimento Especializado do Conteúdo salientamos a perspectiva de Carrillo et al. (2013), que considera todo o Conhecimento do Professor que Ensina Matemática como especializado. A conceitualização do MTSK $^{11}$ proposto por Carrillo et al. (2013), considera que os três subdomínios do domínio do Conhecimento do Conteúdo (CK) são constituintes do Conhecimento Interpretativo (IK). Compreendemos que esse entendimento, amplia a compreensão proposta por Ball et al., (2008), de que o Conhecimento Interpretativo (IK) está associado apenas ao subdomínio do Conhecimento Especializado do Conteúdo (SCK). Outro, aspecto sinalizado no modelo do (MKTS) é que (Ball et al., 2008) não consideram as crenças dos Futuros Professores e Professores que Ensinam Matemática. No modelo do MTKS elas são contempladas, pois na perspectiva de Carrillo et al. (2013), as crenças e conhecimentos desses profissionais influenciam na aprendizagem dos conteúdos, mesmo não estando relacionadas às questões matemáticas, como por exemplo, a gestão da turma (Carrillo et al., 2013). Em relação a essa proposição, entendemos que os estudos de Ball et al. (2008) por considerarem em suas pesquisas a mobilização do Conhecimento Matemático para e no ensino, se preocuparem com a compreensão dos conteúdos matemáticos e a discussão de estratégias de resolução nas aulas de matemática para buscarem interpretar o desenvolvimento do raciocínio dos

\footnotetext{
${ }^{11}$ Mathematic Teachers Specialized Knowledge.
} 
estudantes objetivando a expansão de ideias acerca do objeto a ser ensinado, as crenças e concepções acerca da matemática e da capacidade de aprender matemática desses autores está explicitada, e do mesmo modo, nos contextos nos moldes do ICEM, em que o conhecimento é compreendido como uma produção coletiva que se constitui gradativamente pela troca de ideias, discussões e reflexões entre as pessoas e os artefatos culturais produzidos por elas em um determinado tempo e espaço.

\section{Desenvolvimento do Pensamento Algébrico nos Anos Iniciais}

Blanton e Kaput (2005) pesquisadores pioneiros da abordagem Early Algebra ${ }^{12}$ reconhecem que o desenvolvimento do pensamento algébrico está associado ao processo pelo qual os estudantes generalizam ideias matemáticas a partir de situações particulares. Para esses autores, essas generalizações podem ser demonstradas inicialmente pela linguagem oral por meio da argumentação das próprias ideias e gradativamente por expressões mais formais no decorrer do processo educativo. Essa compreensão é corroborada por pesquisadores desse campo (Radford, 2006; Canavarro, 2009), que compreendem que nessa abordagem a generalização é considerada o cerne do desenvolvimento do pensamento algébrico, porque à medida que os estudantes, a partir de situações particulares, reconhecem a existência de relações entre estruturas, termos e procedimentos para identificar e explicitar o que é comum, expandem suas capacidades de raciocínio e comunicação.

A BNCC (Brasil, 2017) indica algumas dimensões do trabalho com Álgebra a serem exploradas e desenvolvidas nos anos Iniciais do Ensino Fundamental. São elas: o estudo das regularidades, a generalização de padrões, e as propriedades da igualdade. E defende que os conteúdos nos anos iniciais dessa unidade, sejam trabalhados na perspectiva da apresentação de ideias de generalização utilizando variadas formas de expressar essas regularidades, sem recorrer ao uso de letras (Brasil, 2017).

De acordo com a definição de Vale et al. (2011, p. 9), "usamos o termo padrão para nos referir a uma disposição ou arranjo de números, formas, cores ou sons onde se detectam regularidades". As sequências recursivas possuem uma relação recursiva, que permite identificar aspectos variantes e invariantes de um termo para o próximo termo e, portanto, calcular termos próximos dentro de uma sequência (Fiorentini, 2003). Segundo Van de Walle (2009, p. 300) a "descrição que diz como um padrão é modificado de um passo ao passo seguinte é conhecida como relação recursiva". Na perspectiva de Stacey (1989), as generalizações podem ser classificadas em próximas e distantes. A "generalização próxima" ocorre, quando o aluno, escolhe como estratégia para identificar os termos pedidos em uma determinada sequência que envolve padrões, desenhar, escrever ou contar os termos "um a um" ou "passo a passo", ou ainda utilizando uma tabela para registrar o que varia de um termo ao próximo, ou seja, observando a relação recursiva que está acontecendo ao longo da sequência. Enquanto, a "generalização distante" acontece ocorre, quando o estudante elabora

\footnotetext{
12 Termo utilizado por alguns autores da Educação Matemática para designar o campo que estuda acerca dos conteúdos da Álgebra nos anos iniciais.
} 
uma regra ou lei de formação, que possibilite a identificar a caracterização de qualquer termo da sequência. Vale et al. (2011) também concebem que as generalizações podem ser entendidas como próximas ou distantes. Entretanto, Rardford (2006) utiliza a denominação generalização aritmética para a estratégia de contar ou desenhar "passo a passo", e a expressão "generalização algébrica” para se referir à generalização distante.

\section{Contexto e trajetória da pesquisa}

O ICEM é uma comunidade reconhecida por seus integrantes por possuir uma dimensão colaborativa, pautada nos referenciais da insubordinação criativa, que se preocupa com a aprendizagem da matemática na Educação Básica, em especial nos anos iniciais. $\mathrm{O}$ ICEM visa tanto à investigação das práticas pedagógicas escolares quanto à formação dos seus participantes. Os pressupostos teóricos e metodológicos dos estudos desenvolvidos no grupo ICEM estão alinhados à perspectiva do desenvolvimento profissional docente e aos referenciais das pesquisas que consideram a reflexão do professor para e na própria prática. No âmbito da Educação Matemática, a insubordinação criativa está associada às práticas ou atos criativos dos professores em formação que buscam aliviar a opressão da profissão e a melhoria da aprendizagem dos estudantes, mesmo que essas ações sejam contrárias à cultura e as normas pré-estabelecidas do contexto escolar (D’Ambrosio \& Lopes, 2015).

Ao longo do ano de 2019, os professores em formação no ICEM, decidiram elaborar, desenvolver e discutir narrativas de aulas com excertos de áudio e vídeos da etapa de desenvolvimento das tarefas exploratórias de acordo com a abordagem defendida por Canavarro (2009) discutida pelo grupo. Essas discussões, combinados e negociações no ICEM foram aos poucos consolidando a dimensão colaborativa desse contexto e trazendo indícios de que a nossa investigação estava se caracterizando como uma pesquisa formação em um contexto entre iguais (Nóvoa, 2008; Imbernón, 2009), pois para todos nós, professores em formação, participar do ICEM era uma oportunidade de aprender e poder compartilhar conhecimentos.

Participamos dos encontros do grupo, realizados no segundo semestre de 2018 no ano de 2019, e no primeiro semestre de 2020, o que caracteriza um estudo longitudinal, com o objetivo de registrar, por meio de um diário de bordo, vídeos e áudios, as discussões sobre os conteúdos matemáticos elencados, as práticas pedagógicas materializadas e as ressignificações que emergiram neste contexto. A seguir, apresentamos uma síntese das atividades que foram desenvolvidas no grupo no ano de 2019. Salientamos que em todas as atividades houve movimentos de estudo, discussão e reflexão de referenciais teóricos, entretanto enfatizamos nossas análises no encontro realizado em 24/04/2019, em destaque na etapa de estudos dos referenciais do Quadro 1 a seguir.

Quadro 1 - Encontros e atividades desenvolvidas pelos professores no grupo de estudos colaborativo em 2019.

\begin{tabular}{|c|c|}
\hline Datas dos encontros & Atividades desenvolvidas no grupo \\
\hline $13 / 02$ & Apresentação; definição de objetivos, seleção de \\
$07 / 03$ & referenciais para estudo do Pensamento Algébrico \\
\hline
\end{tabular}


DOI: $10.20396 /$ zet.v29i00.8661731

\begin{tabular}{|c|c|}
\hline & e tarefas exploratórias. \\
\hline $\begin{array}{l}10 / 04 \\
24 / 04 \\
22 / 05 \\
08 / 05\end{array}$ & $\begin{array}{l}\text { Retomada dos referenciais da Insubordinação } \\
\text { Criativa e da pesquisa da própria prática para } \\
\text { novos integrantes; Estudo de referenciais do } \\
\text { pensamento algébrico e ensino exploratório. }\end{array}$ \\
\hline $\begin{array}{l}29 / 05 \\
05 / 06\end{array}$ & $\begin{array}{c}\text { Elaboração de tarefas exploratórias para a } \\
\text { generalização em sequências repetitivas e } \\
\text { recursivas, e, sobre os diferentes usos do sinal de } \\
\text { igualdade; Elaboração de trabalhos e apresentação } \\
\text { em eventos da área. }\end{array}$ \\
\hline $\begin{array}{l}19 / 06 \\
26 / 06 \\
03 / 07 \\
17 / 07\end{array}$ & $\begin{array}{l}\text { Discussão sobre o uso de narrativas de aulas e } \\
\text { excertos de áudios e vídeos da etapa do } \\
\text { desenvolvimento (Canavarro, 2009), das tarefas } \\
\text { exploratórias elaboradas no ICEM para subsidiar } \\
\text { as discussões no grupo. }\end{array}$ \\
\hline $07 / 08$ & $\begin{array}{l}\text { Acolhida de novos membros e retomada/ revisão } \\
\text { dos referenciais estudados no } 1^{\circ} \text { semestre } / 2019\end{array}$ \\
\hline $21 / 08$ & $\begin{array}{c}\text { Discussão e finalização das sequências de tarefas a } \\
\text { serem desenvolvidas nas classes dos anos iniciais } \\
\text { de professores do grupo ICEM. }\end{array}$ \\
\hline $\begin{array}{l}11 / 09 \\
18 / 09\end{array}$ & $\begin{array}{l}\text { Organização de evento científico na universidade; } \\
\text { Sistematização dos pontos para nortear a atenção } \\
\text { seletiva }{ }^{13} \text { dos professores do grupo na discussão } \\
\text { das narrativas de aulas. }\end{array}$ \\
\hline $\begin{array}{l}13 / 11 \\
20 / 11 \\
27 / 11 \\
04 / 12 \\
11 / 12 \\
18 / 12\end{array}$ & $\begin{array}{c}\text { Desenvolvimento das tarefas exploratórias com os } \\
\text { estudantes, elaboração e discussão das narrativas } \\
\text { de aulas no grupo. }\end{array}$ \\
\hline
\end{tabular}

Fonte: As autoras 2020.

Em relação aos professores colaboradores desta pesquisa e integrantes do ICEM, registramos a presença de 23 membros desde a constituição do grupo. Entretanto, alguns vinham aos encontros eventualmente, pois a participação nesse espaço era voluntária. Dentre os integrantes que compareceram aos encontros com regularidade, estão dois acadêmicos de licenciatura em Matemática; uma acadêmica de Pedagogia; seis pós-graduandos da área de Educação Matemática; quatro formadores de professores que ensinam Matemática; e sete professores que ensinam Matemática na Educação Básica, sendo três deles nos anos iniciais. Neste texto, os nomes utilizados para representar os participantes do grupo não correspondem aos seus verdadeiros nomes e a investigação foi aprovada junto ao Comitê de Ética em Pesquisa $^{14}$ da Universidade Federal de Santa Catarina.

Para subsidiar a sistematização e as análises das informações deste texto, utilizamos a

\footnotetext{
13 A expressão "atenção seletiva" foi utilizada no ICEM com a mesma compreensão que os Futuros Professores utilizaram para discutir os conhecimentos mobilizados pela professora e estudantes no caso multimídia apresentado em Rodrigues, Cyrino e Oliveira (2018).
}

${ }^{14}$ CAAE: 13727819.5.0000.0121; Número do Parecer: 3.397.17. 
pesquisa narrativa na perspectiva de Clandinin e Connelly (2011), a mesma da abordagem utilizada para analisar os constructos ao longo do estudo longitudinal. A Pesquisa Narrativa concebe que a educação está intrinsecamente relacionada à experiência e à vida. De acordo com os autores, para pensar narrativamente sobre o fenômeno e compor os textos da pesquisa, os pesquisadores precisam estar no campo da investigação, pois nessa perspectiva, a pesquisa é uma maneira de entender e questionar a experiência através da colaboração entre pesquisadores e participantes, ao longo do tempo, e em interações sociais (Clandinin \& Connelly, 2011).

Os textos selecionados pelos professores do grupo para discutirem acerca do pensamento algébrico foram compartilhados online entre os integrantes e traziam além de referenciais teóricos e experiências de aprendizagens de Futuros Professores, Formadores de Professores e Professores que Ensinam Matemática de outras comunidades ou grupos de estudos. Para dinamizar as leituras e discussões, primeiramente os professores realizavam uma leitura individual e sinalizavam o que seria discutido coletivamente. Para registrar as interações dialógicas do grupo que subsidiaram a produção dos dados deste texto realizamos a gravação do encontro mencionado e realizamos a transcrição dos áudios e vídeos das discussões. Para a análise das informações fizemos várias leituras e o cotejamento de falas com as reflexões dos professores e a interpretação destes na perspectiva dos referenciais teóricos da base de conhecimentos para o ensino (Shulman, 1986); do Conhecimento Matemático para o Ensino (Ball et al., 2008), em especial aos aspectos que se referem Conhecimento Interpretativo (IK) associado ao Conhecimento Especializado do Conteúdo (SCK) (Carrillo, 2013; Ribeiro, 2017).

\section{Conhecimentos mobilizados para o desenvolvimento da ideia de generalização de padrões em sequências recursivas}

Evidenciamos, na etapa de estudo dos referenciais acerca do desenvolvimento do pensamento algébrico, no grupo ICEM, as seguintes três temáticas de estudos interligadas: 1) o uso do sinal de igual com a ideia de equivalência; 2) o reconhecimento de padrões e motivos em sequências repetitivas; e 3) a identificação de termos, generalização próxima e distante em sequências recursivas. Entretanto, o foco deste artigo consiste na análise do modo como o Conhecimento Matemático para o Ensino foi mobilizado, no estudo de padrões em sequências recursivas, descrevemos a seguir de modo sucinto alguns aspectos acerca do estudo da generalização em sequências repetitivas por entendermos que eles contribuem para introduzir a generalização de padrões em sequências recursivas.

$\mathrm{Na}$ continuidade o grupo estudou os conteúdos relativos à exploração de padrões e generalização em sequências repetitivas e recursivas apresentados no livro de Van de Walle (2009). Segundo esse autor, as atividades, em contextos figurativos, acerca de padrões repetitivos, de crescimento e decrescimento, propiciam uma diversidade de situações onde o professor pode fazer explorações ricas e variadas em conjunto com os estudantes para caracterizar o motivo ou grupo de repetição das sequências repetitivas, os processos recursivos utilizados para encontrar os termos próximos de uma sequência e a lei de formação 
que permita identificar um termo distante qualquer, mesmo que este não tenha o termo anterior como parâmetro em uma sequência recursiva.

Para estudar os conceitos de padrão, motivo e sequências repetitivas, os professores utilizaram blocos lógicos. Cada dupla iria iniciou uma sequência e os demais integrantes identificavam o motivo da sequência criada. No decorrer das sequências construídas pelas duplas, a quantidade de elementos dos grupos de repetição e a complexidade dos arranjos desses grupos foram aumentando. Isso contribuiu para o entendimento de que a complexidade dos padrões depende do número de elementos do motivo e da tipologia das repetições presentes, conforme indicado em Van de Walle (2009). Na sequência, dentre os textos estudados pelos professores em formação no ICEM para fundamentar as questões que emergiram acerca da identificação de termos, generalização próxima e distante, em sequências recursivas, trazemos o artigo "O pensamento algébrico e a descoberta de padrões na formação de professores" (Vale \& Pimentel, 2013). O referido texto apresenta uma discussão sobre a importância dos padrões para o desenvolvimento do pensamento algébrico, através de uma experiência de uma professora do $3^{\circ}$ ano no desenvolvimento de uma sequência didática. Entretanto as autoras sinalizam que esta atividade pode ser desenvolvida com as devidas adaptações em outras turmas dos anos iniciais. $\mathrm{O}$ artigo inicia com uma fundamentação teórica com foco na formação de professores, em relação ao ensino da álgebra na perspectiva do desenvolvimento do pensamento algébrico a partir da exploração de padrões. Na sequência, as autoras apresentam uma proposta didática com a finalidade de servir de suporte à abordagem de tarefas com padrões, visando o desenvolvimento do pensamento algébrico. E defendem que se nós professores temos a intenção de desenvolver a capacidade de raciocinar e resolver problemas dos estudantes, precisamos lhes propiciar tarefas que não os limitem à mera aplicação de procedimentos, mas que favoreçam o estabelecimento de conexões e oportunidades de comunicação (Vale \& Pimentel, 2013).

No decorrer do texto, as autoras apresentam uma tarefa, caracterizada pelas autoras de nível dois, desenvolvida com estudantes do $3^{\circ}$ ano dos anos iniciais, e tinha como objetivo a determinação da quantidade de estrelas de qualquer termo de uma sequência recursiva, conforme mostra a Figura 1 a seguir.

Considera a sequência de estrelas em $\mathrm{L}$.

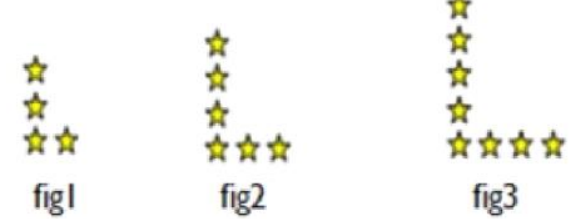

I. Quantas estrelas tem o $4^{\circ} \mathrm{L}$ ?

2. Quantas estrelas são necessárias para construir a $20^{2}$ figura? Explica como pensaste. Discute com o colega do lado.

3. Explica por palavras tuas de quantas estrelas precisas para desenhar uma figura qualquer na sequência. 
DOI: 10.20396/zet.v29i00.8661731

Figura 1 - Tarefa sobre sequências que subsidiou as discussões do grupo.

Fonte: Vale e Pimentel (2013, p.111).

A respectiva tarefa, de acordo com o texto, visava o reconhecimento de padrões e a generalização através de regras formuladas pelas próprias crianças, recorrendo ou não à simbologia. Segundo as autoras, usualmente neste tipo de tarefa os estudantes realizam uma conversão numérica para identificar alguma regularidade ou padrão entre as figuras. E, elas ressaltam que eles conseguem facilmente descobrir a regra a partir da recorrência, ou seja, cada termo é obtido adicionando-se duas unidades ao termo anterior. Essa seria uma generalização próxima, ou de acordo com Radford, (2006), aritmética. O desafio está na identificação de termos distantes, a partir da elaboração de uma regra sem ser preciso recorrer ao termo anterior, denominada pelas autoras como distante, ou também por generalização algébrica (Radford, 2006). Para tanto, as autoras recomendam que o professor construa juntamente com os estudantes na lousa uma tabela (Figura 2), a partir da observação do que é invariante na estrutura de cada figura. A construção da tabela poderá auxiliar os estudantes dos anos elementares a compreenderem o que varia e o que é invariante nos termos subsequentes e na resolução do desafio proposto.

$\mathrm{Na}$ perspectiva do desenvolvimento do Conhecimento para o Ensino Matemático, compreendemos que além do Conhecimento Comum do Conteúdo (CCK), o Professor que ensina Matemática precisa evidenciar em suas práticas letivas para o ensino dos conteúdos matemáticos os demais subdomínios do domínio do Conteúdo (CK) e do domínio Pedagógico do Conteúdo (PCK) do MKT proposto por Ball et al. (2008), a partir da base de conhecimentos para o ensino (Shulman, 1986). E, em especial, o que atribui sentido às estratégias de resolução dos estudantes, o reconhecido como Conhecimento Interpretativo (IK), associado ao Conhecimento Especializado do Conteúdo (SCK).

Ao lermos essa parte do texto, o professor Marcelo ${ }^{15}$ sugeriu que tentássemos identificar outras possibilidades para solucionar o desafio proposto pelas autoras, ou seja, determinar um termo qualquer distante, sem precisar recorrer aos termos anteriores. Então, a professora Sophia, sugeriu que cada dupla poderia ser constituída por professores que trabalhassem no mesmo segmento da Educação Básica, ou por licenciandos, assim as possibilidades trazidas estariam mais coerentes com o segmento em que esses professores estariam lecionando e poderiam "pensar" de acordo com os conhecimentos que seus alunos já tivessem acessado. A professora Vera, complementou que essa organização também oportunizaria mais trocas entre os participantes de cada dupla e depois poderíamos comparar se haveria aproximações ou diferenças entre as estratégias apresentadas pelas diferentes composições (anos iniciais, anos finais, licenciandos e formadores). Os professores presentes sentiram-se desafiados e foram se agrupando em duplas ou trios, com o desafio de fazer uma generalização e elaborar uma lei de formação diferente da apresentada pelas autoras Vale e Pimentel (2013).

Depois de alguns minutos uma dupla, constituída por professores especialistas, que lecionam

\footnotetext{
${ }^{15}$ Os nomes utilizados não correspondem aos nomes verdadeiros dos professores participantes do ICEM.
} 
nos anos finais do Ensino Fundamental e no Ensino Médio, perguntou se já poderia compartilhar a sua estratégia, as demais duplas sinalizaram que sim, e então, o professor Marcelo começou a expor a estratégia da dupla oralmente, mas houve dificuldade de compreensão, e a professora Kátia, uma das professoras dos anos iniciais comentou: Assim, oralmente, eu não estou conseguindo compreender a estratégia de vocês. Eu não consigo entender desse jeito. Então houve o consenso entre o grupo de que era preciso apresentar na lousa as estratégias encontradas. Quando o professor Marcelo foi a até a lousa, escreveu e explicou o modo como ele e a colega, a professora Rose pensaram. Nessa situação os participantes vivenciaram as dificuldades dos estudantes para compreenderem tais estratégias, sem a devida sistematização das ideias e perceber diferentes hipóteses de resolução para a mesma tarefa. E percebemos que esse choque de realidades profissionais, fez com que o professor de Matemática, Marcelo, que estava apresentando a primeira estratégia, habituado a ensinar Álgebra nos anos finais do Ensino Fundamental e Ensino Médio, refletisse sobre a importância do registro para que suas ideias fossem compreendidas, isso se relaciona de acordo com o modelo proposto por Ball et al., (2008), ao Conhecimento do Conteúdo e de Ensino (KCT e ao Conhecimento do Conteúdo e dos Estudantes (KCS). E que, a professora dos Anos Iniciais, Vera, que embora tenha conhecimento sobre Álgebra, não estava habituada a ensiná-la, pudesse aprofundar e expandir as ideias associadas ao o Conhecimento Comum do Conteúdo (CCK) que está relacionado ao "saber fazer". Na sequência, uma a uma das estratégias foram demonstradas na lousa pelas duplas. Essa dinâmica foi importante para que pudéssemos vivenciar as dificuldades dos estudantes ao tentar compreender as estratégias ou explicações dos professores, quando não estão acompanhadas da devida sistematização das ideias na lousa. Outro aspecto que ficou bem evidente nos comentários explicitados no grupo no momento da socialização das hipóteses das duplas, foi a percepção da possibilidade de diferentes estratégias de resolução para a tarefa proposta, que a princípio, parecia ter apenas uma solução.

Sistematizamos na Tabela 1, a seguir as diferentes expressões algébricas discutidas no grupo a partir da socialização das estratégias desenvolvidas pelas duplas. E, na sequência, trazemos o detalhamento de cada uma dessas estratégias validadas pelos professores do ICEM. Cada uma das duplas como apresentaremos era formada por professores com diferentes formações e atuações.

Tabela 1 - Estratégias de resolução elaboradas pelos professores.

\begin{tabular}{cc}
\hline Dupla & Estratégias representadas por expressão algébrica \\
\hline 1 & $2+2 \cdot n$ \\
\hline 2 & $2 .(\mathrm{n}+1)$ \\
\hline 3 & $(\mathrm{n}+1)^{2}-\left(\mathrm{n}^{2}\right)+1$ \\
\hline 4 & $(\mathrm{n}+1) .(\mathrm{n}+2)-[(\mathrm{n}(\mathrm{n}+1)]$ \\
\hline 5 & $4+2 .(\mathrm{n}-1)$ \\
\hline
\end{tabular}

Fonte: As autoras, 2020.

A dupla de número 1, composta por professores do Ensino Fundamental II, como estratégia de resolução fixou o número 2, como parte invariante, de todas as figuras, sendo as duas estrelas da coluna, como pode ser visto na Figura 2, a seguir.

Expressão algébrica: $2+2 . n$ 


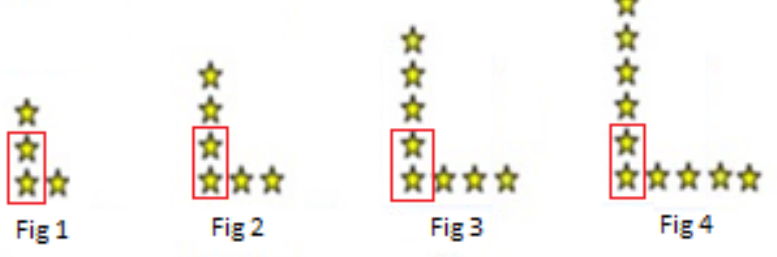

Figura 2 - Estratégia de resolução da dupla 1. Fonte: As autoras 2020.

Ao considerar as duas estrelas fixas, a dupla mostrou ao grupo que havia uma correspondência entre os elementos que variavam, tanto da linha quanto da coluna, e o número da posição da figura. Ou seja, a quantidade de estrelas sobrantes, da linha e da coluna aumentava sucessivamente, caracterizando um padrão de crescimento, e era correspondente ao número da figura na sequência. Portanto, a parte que varia é sempre o dobro do número da figura. $\mathrm{O}$ que corresponde à expressão algébrica 2+2.n.

A dupla comentou ainda, que havia escolhido essa estratégia por compreender que tal expressão seria mais acessível às crianças do terceiro ano, pois a partir da seleção das duas estrelas na primeira coluna como a parte invariante, fica mais evidente a percepção de que as demais estrelas sobrantes da linha e da coluna correspondem à ordem do termo na sequência. Segundo Rose, uma das professoras da dupla, "as crianças iriam perceber que no primeiro termo além das duas estrelas selecionadas, sobra mais uma estrela na coluna e na linha. Enquanto que na segunda figura sobram duas estrelas na coluna e outras duas na linha, $e$ assim sucessivamente. Então, as crianças iriam perceber com facilidade a correspondência entre o número da figura e a quantidade de estrelas que deveria constar na linha e na coluna desse termo." (Transcrição de Áudio, 24/04/2019).

$\mathrm{Na}$ argumentação da professora Rose, fica evidente o movimento de "tentar" se colocar no lugar dos estudantes dos anos iniciais para interpretar possíveis motivos para a escolha das suas estratégias de resolução. Essa preocupação explicitada pela professora, evidencia a mobilização do Conhecimento Interpretativo (IK). Esse conhecimento está associado à ação do professor para e no ensino da matemática, e é considerado um dos conhecimentos que compõem o Conhecimento Especializado do Conteúdo (SCK), pois é próprio do professor que ensina matemática (Ball et al, 2008).

No excerto com a explicação da professora Rose, podemos perceber ainda indícios da mobilização dos três conhecimentos do domínio do Conhecimento Pedagógico do Conteúdo (PCK), pois ao tentar elaborar uma estratégia pensando nos estudantes do terceiro ano, os professores dessa dupla demonstram reconhecer como a matemática escolar está organizada no currículo dos anos iniciais, essa percepção está associada ao Conhecimento do Conteúdo e do Currículo (KCC); ao avaliar os ganhos de utilizar as duas estrelas fixas na primeira coluna, os professores mostram indícios do Conhecimento do Conteúdo e do Ensino (KCT), e, por fim, evidenciam indícios da mobilização do Conhecimento do Conteúdo e dos Estudantes (KCS) ao antecipar que as crianças poderiam perceber após fixar as duas estrelas na primeira 
coluna, que os demais elementos que variam tanto da linha quanto da coluna aumentam sucessivamente de acordo com o número da figura.

Também nos possibilita inferir que as trocas com os professores dos anos iniciais nesse espaço formativo favoreceram que tais estratégias de resolução fossem pensadas e consideradas por essa dupla, constituída por professores que lecionam nos anos finais e no Ensino Médio da Educação Básica.

Todavia, ao ouvir a argumentação da professora Rose, as professoras que lecionam nos anos iniciais afirmaram que provavelmente, as crianças do terceiro, quarto e quinto anos não iriam identificar como a parte invariante, apenas as duas primeiras estrelas da coluna. $\mathrm{Na}$ compreensão das professoras, as crianças iriam selecionar todas as estrelas da primeira figura para depois verificar o que estaria variando nas próximas. Nesse posicionamento das professoras dos anos iniciais percebe-se a apropriação e a mobilização do Conhecimento Comum do Conteúdo (CCK), e do Conhecimento do Conteúdo e dos Estudantes (KCS), pois, elas conseguem antecipar com segurança a possível estratégia a ser utilizada pelas crianças. $\mathrm{Na}$ conceitualização de Ball, et al. (2008) essas percepções estão relacionadas ao conhecimento das expectativas de aprendizagem dos estudantes, de acordo com o ano que estão cursando, as hipóteses de resolução, que provavelmente, emergem nas classes desse ano, e os possíveis obstáculos que eventualmente podem ser constituídos no processo de ensino de um determinado conteúdo. E, corroboram com as evidências sinalizadas nos estudos desenvolvidos por Ball, et al. (2008) sobre as trocas de experiências entre os professores de matemática de diferentes segmentos e modalidades da Educação Básica. As pesquisas desses autores apontam que o Conhecimento Especializado do Conteúdo (SCK), mobilizado para e no ensino da matemática pode ser desenvolvido e compartilhado pelos professores. E, das pesquisas acerca dos contextos formativos híbridos, por esses contextos formativos que oportunizarem a constituição de relações não formais, favorecem a expansão das interações dialógicas entre os professores, e consequentemente, a mobilização e o desenvolvimento do conhecimento para o ensino por meio das discussões acerca da ação docente. Essas percepções foram consideradas em estudos no campo da Educação Matemática em de espaços de formação constituídos por professores iniciantes e experientes. E, sinalizaram que as trocas entre esses professores, seja no início ou em outra etapa da profissão docente, contribuem para a conscientização de que os conhecimentos para o ensino do Professor que Ensina Matemática repercutem na aprendizagem da matemática pelos estudantes (Fiorentini, 2019).

A dupla a qual identificamos pelo número 2, era composta por pós-graduandos e professores do Ensino Fundamental II. E apresentou outro raciocínio diferente do demonstrado anteriormente, como pode ser visto na Figura 3, a seguir.

Expressão algébrica: 2. $(\mathrm{n}+1)$ 

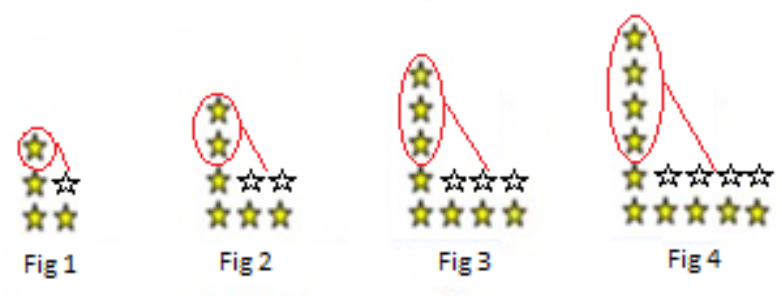

Figura 3 - Estratégia de resolução da dupla 2. Fonte: As autoras 2020.

Essa dupla considerou que o número de estrelas na primeira linha corresponde ao número da figura acrescido de uma estrela, e que a partir da segunda figura é possível obter uma distribuição retangular, acrescentando à segunda linha a quantidade de estrelas correspondente ao número da figura. Outra questão que a dupla apontou foi que a quantidade de estrelas a serem acrescentadas na segunda linha corresponde à quantidade de estrelas sobrantes na primeira coluna. A expressão algébrica 2. $(n+1)$ é equivalente a expressão $2+$ 2.n encontrada pela dupla 1. Assim, pela semelhança com a expressão da dupla anterior, esta estratégia a princípio não gerou muitas discussões no grupo. Mas no decorrer da socialização, os professores entenderam que essa percepção trazida pela dupla, de que a partir da segunda figura a configuração das estrelas das duas linhas possui uma representação retangular, ampliou a percepção geométrica e o reconhecimento de que o desenvolvimento do pensamento geométrico contribui para ampliar as ideias matemáticas, e que é importante que os professores que ensinam matemática trabalhem o desenvolvimento desse pensamento em conjunto com os conteúdos do pensamento algébrico e aritmético. Essa percepção evidencia indícios da mobilização do Conhecimento do Conteúdo no Horizonte (HCK), (Ball et al., 2008).

Por sua vez, a estratégia desenvolvida pela dupla de número 3, apresentada pelos licenciandos Pedro e Rodrigo, acadêmicos da licenciatura em matemática, foi considerada a "mais complexa" pelos professores do grupo, por ter em sua expressão um produto notável e esse conteúdo não estar presente no currículo dos anos iniciais. Os licenciandos, mencionaram que partiram da solução geométrica representada na Figura 4, a seguir, para chegar a expressão algébrica $(n+1)^{2}-\left(n^{2}\right)+1$, conforme a Tabela 1 .

Expressão algébrica: $(n+1)^{2}-\left(n^{2}\right)+1$

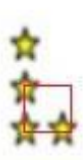

Fig 1

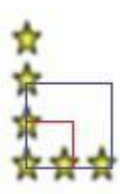

Fig 2

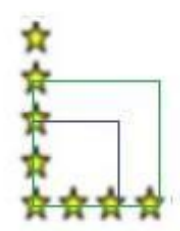

Fig 3

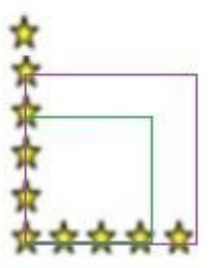

Fig 4

Figura 4 - Estratégia de resolução da dupla 3. Fonte: As autoras 2020. 
Eles consideraram duas distribuições quadrangulares a partir das duas últimas estrelas da linha de uma das figuras da sequência. A regularidade percebida pelos licenciandos foi que a base da distribuição quadrangular da figura interna, a partir da figura dois corresponde ao número da figura na sequência, e que subtraindo-se a área da distribuição quadrangular interna, da externa, de qualquer termo da sequência, com exceção do primeiro, sempre sobram três estrelas, sendo duas estrelas na coluna e uma estrela na linha desta figura. Desse modo, seria possível identificar a quantidade de estrelas de um termo qualquer da sequência sem precisar recorrer a figura anterior.

Essa estratégia, gerou a necessidade de mais explicações. Os licenciandos tiveram que reexplicar várias vezes o modo como pensaram para tornar sua estratégia acessível aos professores do grupo, e os professores mais experientes precisaram contribuir para que os demais colegas pudessem compreender a estratégia desta dupla. Alguns professores sugeriram a demonstração geométrica na lousa para propiciar a compreensão dessa estratégia pelo grupo. Isso vem ao encontro do que foi sinalizado nos estudos realizados por Rodrigues, Cyrino e Oliveira (2018), de que os Futuros Professores, comparados aos Professores mais Experientes, estão iniciando o processo de construção de conhecimentos para explicar e prever como as informações serão assimiladas pelos estudantes. Esses conhecimentos estão relacionados ao Conhecimento Especializado do Conteúdo (SCK). Os conhecimentos desse subdomínio são explicitados nas ações docentes do professor que ensina matemática e vão se constituindo e se desenvolvendo cada vez mais ao longo da docência. E ele, repercute nas ações voltadas para a escolha da abordagem pedagógica e dos recursos escolhidos pelo professor para promover a aprendizagem do conteúdo a ser ensinado, mobilizando o Conhecimento do Conteúdo e do Ensino (KCT), e, consequentemente mobiliza o Conhecimento do Conteúdo e dos Estudantes (KCS), e o Conhecimento do Conteúdo e do Currículo (KCC), (Ball et al, 2008). Por isso, na nossa compreensão, concordamos com a perspectiva mais ampliada sinalizada no (MKST) e em outros estudos acerca do desenvolvimento profissional docente no âmbito da Educação Matemática, de que todo o Conhecimento do Professor que Ensina Matemática é Especializado, e que o Conhecimento Interpretativo (IK) que caracteriza a especificidade desse profissional está associado aos três subdomínios do Conhecimento do Conteúdo (CK) do MKTS (Carrillo et al., 2013; Ribeiro, 2017).

Entretanto, embora os acadêmicos e os demais integrantes do grupo tenham reconhecido que a expressão algébrica dessa hipótese de resolução seria complexa para os estudantes dos anos iniciais, consideraram a sua representação geométrica acessível e importante para promover a discussão com as crianças. O desenvolvimento dessa tarefa no grupo possibilitou que os licenciandos experienciassem a ação de ensinar e de se fazer compreender, e a refletir sobre formas diferentes para explicar, argumentar e expor suas estratégias. A discussão acerca do reconhecimento da distribuição geométrica como suporte para a formulação aritmética e generalização algébrica do padrão, evidencia a articulação de diferentes campos da matemática (aritmética, álgebra, geometria), expandindo a compreensão dos objetos e conceitos matemáticos pelos professores em formação no ICEM, e sinaliza que 
os licenciandos ao elaborar essa estratégia mobilizaram o Conhecimento Comum do Conteúdo (CCK) associado à Álgebra e a linguagem algébrica, mas não para o ensino, esse conhecimento, não é próprio do professor, pode inclusive ser usado por outros profissionais. E, ao fazerem conexões do conteúdo de padrões em sequências recursivas, com conceitos mais elaborados da própria Álgebra, abordados nos anos finais do Ensino Fundamental, e conceitos da Geometria, os licenciandos evidenciaram indícios da mobilização do Conhecimento do Conteúdo no Horizonte (HCK), (Ball et al., 2008). Com relação à dificuldade sinalizada pelos licenciandos de explicitar a estratégia da dupla de uma forma compreensível aos demais professores, e, a contribuição dos professores mais experientes para a compreensão da referida estratégia, compreendemos que são evidências que confirmam que o Conhecimento Especializado do Conteúdo (SCK) se constitui e se desenvolve na ação docente (Ball et al., 2008).

A dupla 4, composta pelos professores formadores da universidade, partiu da solução geométrica, apresentada na Figura 05, a seguir.

Expressão algébrica: $(\mathrm{n}+1) \cdot(\mathrm{n}+2)-[(\mathrm{n}(\mathrm{n}+1)]$

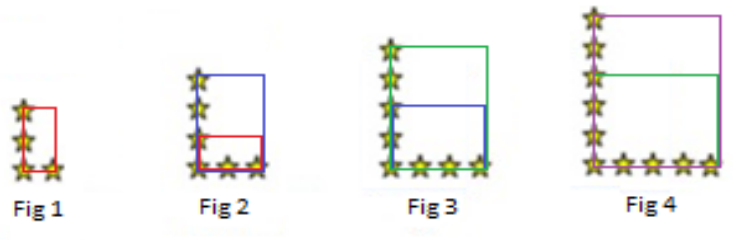

Figura 5 - Estratégia de resolução da dupla 4. Fonte: As autoras em 2020.

Essa dupla percebeu que completando as estrelas que estavam faltando na figura seria possível formar uma distribuição de estrelas retangular fora e outra distribuição retangular dentro. A subtração entre as quantidades de estrelas nas duas distribuições retangulares seria equivalente ao número de estrelas da figura. Para tanto é preciso considerar que o número de estrelas da linha é sempre um a mais do que o número da figura $(n+1)$, enquanto que o número de estrelas na coluna é sempre duas a mais do que o número da figura $(n+2)$, encontrando a expressão algébrica $(n+1) .(n+2)-[(n(n+1)]$.

Para montar a expressão algébrica, a dupla enfatizou que é preciso considerar que o número de estrelas da linha é sempre um a mais do que o número da figura $(n+1)$, enquanto que o número de estrelas na coluna é sempre duas a mais do que o número da figura $(\mathrm{n}+2)$, encontrando a expressão algébrica $(n+1)$. $(n+2)-[(n(n+1)]$.

A própria dupla ao apresentar, explicitou que essa estratégia não seria uma solução encontrada pelas crianças dos anos iniciais, estaria mais no âmbito dos estudantes dos anos finais. Todavia geometricamente seria interessante para as crianças perceberem outras possibilidades de resolução. Essas considerações da dupla evidenciam indícios da mobilização dos três conhecimentos do domínio do Conhecimento Específico do Conteúdo (CK), o Conhecimento Comum do Conteúdo (CCK), que está associado ao conhecimento do 
uso da linguagem algébrica, o Conhecimento do Conteúdo no Horizonte (HCK), pois, percebe-se uma apropriação do conhecimento matemático além do conteúdo discutido, tendo em vista que a dupla fez relações desse conteúdo com o desenvolvimento ou a ampliação do pensamento algébrico e geométrico e com outros tópicos da matemática, sinalizando saber "situar esse conceito" em outros momentos e fazer conexões com outros conceitos da matemática que serão abordados em anos posteriores; e o Conhecimento Especializado do Conteúdo (SCK) ao perceberem que, mesmo não sendo uma solução a ser encontrada pelas crianças, essa estratégia contribui para a identificação e o reconhecimento da relação recursiva da sequência e a expansão das ideias matemáticas envolvidas. E ainda, que a possibilidade de expandir a discussão a partir da representação geométrica da relação recursiva, poderá repercutir na compreensão de outros conteúdos abordados no currículo da disciplina de matemática. Essa percepção está associada ao Conhecimento "Especializado" do Conteúdo, porque é um conhecimento que não é necessário para outros fins, a não ser para o ensino. E a sua mobilização, envolve conhecer a matemática de forma detalhada, entendendo os "porquês" de um procedimento, a importância de diferentes estratégias e interpretações para a resolução de uma situação problema, e os possíveis ganhos para a compreensão e as conexões dos conceitos a partir delas.

As considerações trazidas por essa dupla levou o grupo a discutir que talvez os estudantes do sétimo, oitavo ou nono ano conseguiriam chegar à generalização algébrica. Essa discussão evidencia indícios da mobilização do Conhecimento do Conteúdo e do Currículo (KCC), esse conhecimento está relacionado ao reconhecimento da distribuição dos conteúdos matemáticos nos programas escolares e permitem ao professor antecipar quais conteúdos da sua disciplina os estudantes da sua classe tiveram acesso ou deveriam ter acessado, e, em que anos posteriores da Educação Básica o conteúdo que irá ensinar será abordado ou utilizado para novas apropriações conceituais, de acordo com os documentos oficiais como a BNCC (Brasil, 2017).

A dupla de número 5, composta por professoras dos anos iniciais, como mencionamos nas discussões da primeira dupla, considerou que as crianças iriam fixar a primeira figura e procurar ver o que variou, a partir dela, nos próximos termos. Assim, de acordo com essa compreensão, perceberiam que a cada termo aumentaria na linha e na coluna uma quantidade de estrelas correspondente a um número a menos do que o número da figura, conforme mostramos na Figura 6 a seguir.

Expressão Algébrica: 4 + 2. $(\mathrm{n}-1)$

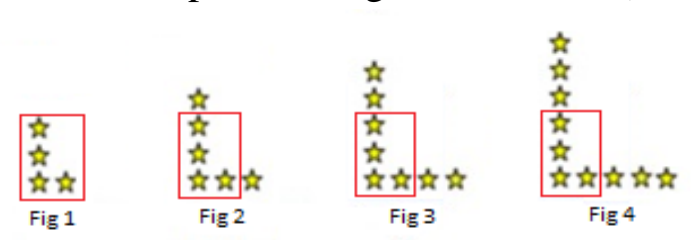

Figura 6 - Estratégia de resolução da dupla 5.

Fonte: As autoras em 2020. 
DOI: $10.20396 /$ zet.v29i00.8661731

As professoras desta dupla evidenciaram na sua argumentação indícios da mobilização do Conhecimento Comum do Conteúdo (CCK), que está associado ao conhecimento do uso da linguagem algébrica, e ampliaram a discussão no coletivo do grupo trazendo os conhecimentos de suas experiências enquanto professoras deste nível de ensino. Elas argumentam que esta seria a estratégia que as crianças tenderiam a utilizar, pois provavelmente utilizariam a estratégia de "carimbar" a primeira figura nas demais para identificar o que iria variar ou seria invariante na segunda figura, depois na terceira, na quarta, e assim, sucessivamente. Todavia, as professoras dos anos iniciais presentes, reconheceram que a expressão algébrica $4+2$. (n - 1) não seria a "mais acessível" às crianças, por ser uma expressão mais elaborada em comparação com as expressões apresentadas pelas duplas 1 e 2, mas mesmo precisando fazer uso da adição e da multiplicação, e provavelmente, ser necessário maior intervenção pedagógica, ainda assim, essa seria a estratégia mais provável que as crianças iriam desenvolver. Essa argumentação dos anos iniciais evidencia indícios da mobilização do Conhecimento Comum do Conteúdo (CCK), que está associado ao conhecimento do uso da linguagem algébrica, e ampliou discussão no coletivo do grupo ao compartilhar os conhecimentos de suas experiências enquanto professoras deste nível de ensino.

No movimento de verificar a estratégia mais acessível aos estudantes, o grupo percebeu que mesmo a estratégia que tinha a expressão algébrica mais complexa, $(n+1)$. (n $+2)-[(n(n+1)]$, tinha uma representação geométrica, que pareceu ser possível ser construída pelas crianças. Deste modo, os professores entenderam que era importante promover a socialização coletiva das estratégias criadas pelas crianças, mas também oportunizar outras estratégias diferentes das que elas trazem. Pois, o movimento de tentar elaborar explicações para a compreensão delas, contribui para a expansão das ideias matemáticas. Essa reflexão evidencia a compreensão pelos professores em formação no ICEM de que as conexões dos conteúdos matemáticos para a expansão das ideias dos estudantes.

Esse movimento de elaboração de estratégias em duplas, sistematização e validação das hipóteses no coletivo do grupo contribuiu para que os professores do ICEM vivenciassem as etapas da abordagem do ensino exploratório proposta por Canavarro (2009). Essa vivência oportunizou a reflexão sobre a importância da comunicação das ideias matemáticas dos estudantes em suas aulas. Outro aspecto que o grupo percebeu foi a necessidade de o professor conhecer antecipadamente as estratégias dos estudantes para organizar a ordem da socialização delas na lousa, e assim, antecipar mediações que possibilitem o desenvolvimento das ideias que possam emergir nas discussões, de modo a potencializar compreensão do conteúdo pela classe. Essas ações contribuem para que os estudantes compreendam que o "erro" faz parte do processo de aprendizagem, e é parte constituinte do processo de resolução. Além de propiciar a promoção das interações dialógicas e a participação dos estudantes nesses momentos de socialização e discussão nas aulas de matemática. Essas compreensões evidenciam a mobilização de indícios do Conhecimento Interpretativo (IK), que está associado ao Conhecimento Especializado do Conteúdo (SCK) na conceitualização de Ball et al. (2008). E o reconhecimento da distribuição geométrica como suporte para a formulação 
aritmética e generalização algébrica do padrão evidencia preocupação do grupo com a articulação de diferentes campos da matemática (aritmética, álgebra, geometria), isso permitiu a expansão e a compreensão dos objetos e conceitos matemáticos, e evidencia a mobilização dos conhecimentos do Domínio Específico do Conteúdo (CK), (Ball et al., 2008).

\section{Considerações Finais}

Neste estudo buscamos analisar como os conhecimentos para o ensino da matemática foram mobilizados em momentos de estudos de um grupo colaborativo, acerca do desenvolvimento do Pensamento Algébrico nos anos iniciais. Os excertos, discussões e análises acerca dos conhecimentos mobilizados pelos professores em formação nos momentos de estudos, evidenciam indícios de conhecimentos do domínio do Conhecimento do Conteúdo (CK), e do domínio do Conhecimento Pedagógico do Conteúdo (PCK). Por exemplo, ao se preocuparem em explicitar suas estratégias de modo acessível às crianças, evidenciam indícios da mobilização do Conhecimento Comum do Conteúdo (CCK), do Conhecimento Especializado do Conteúdo (SCK), do Conhecimento do Conteúdo e do Ensino (KCT), e do Conhecimento do Conteúdo e dos Alunos (KCS). E, quando os professores estabelecem conexões com outros conteúdos matemáticos e reconhecem em quais anos posteriores determinadas expressões poderiam emergir das estratégias apresentadas pelos estudantes, sinalizam indícios da mobilização do Conhecimento do Conteúdo no Horizonte (HCK) e o Conhecimento do Conteúdo e do Currículo (KCC) (Ball et al., 2008).

Destacamos que as duplas dos licenciandos, formadores e dos professores do Ensino Fundamental II evidenciaram mais indícios dos conhecimentos do Domínio Específico do Conteúdo (CK), enquanto as duplas das professoras dos anos iniciais mostraram uma preocupação maior em como abordar e contextualizar esses conteúdos, evidenciando em seus relatos o quanto consideram relevante fazer a relação com os subdomínios do domínio Pedagógico do Conteúdo (PCK), em especial, o Conhecimento do Conteúdo e dos Estudantes (KCS), pois é a partir dele que elaboram as tarefas a serem desenvolvidas com as crianças. Essa preocupação das professoras dos anos iniciais, consequentemente, provocou a mobilização do Conhecimento Especializado do Conteúdo (SCK), é esse conhecimento que vai oportunizar que o professor faça as melhores escolhas em relação à abordagem para o ensino, ao tipo e nível das tarefas que irá propor aos estudantes para alcançar os objetivos propostos em seu planejamento e possibilitar a aprendizagem dos conteúdos matemáticos pelos estudantes. Essas percepções e ações docentes do Professor que Ensina Matemática são decorrentes do Conhecimento Interpretativo (IK), e é esse Conhecimento que caracteriza a especificidade das ações para e no ensino do conteúdo matemático (Ball et al., 2008). E, por ser próprio do Professor que Ensina Matemática, e constitui o cerne do Conhecimento Especializado do Professor que Ensina Matemática (Carrillo, et al., 2013; Ribeiro, 2017).

Outra percepção evidenciada foi a preocupação dos professores em utilizar diferentes representações do mesmo objeto matemático para oportunizar a compreensão das suas ideias. 
As duplas buscaram fazer a transição entre a representação algébrica, geométrica e linguagem natural das suas estratégias. Esse movimento evidencia a mobilização dos três conhecimentos do domínio do Conteúdo (CK), os conhecimentos (CCK, SCK e HCK), e os três conhecimentos do domínio Pedagógico do Conteúdo (PCK), os conhecimentos (KCS, KCT e KCC) de acordo com Ball et al. (2008). A mobilização desses conhecimentos aponta para a importância de considerarmos, na formação de Professores que Ensinam Matemática, tempo e espaço para oportunizar a comunicação matemática, a argumentação e a discussão de estratégias elaboradas pelos estudantes sobre os conteúdos matemáticos que, neste estudo, ficaram delimitados ao desenvolvimento da generalização de padrões em sequências recursivas. Essa dinâmica, pautada no trabalho colaborativo e na discussão coletiva acerca da compreensão e do ensino de conteúdos matemáticos, contribui também para a reflexão sobre a própria prática e à problematização da profissão docente. Assim, interpretamos que esses momentos de estudo no grupo ICEM propiciaram a mobilização de conhecimentos voltados ao desenvolvimento profissional docente dos Professores que Ensinam Matemática.

\section{Referências}

Ball, D., Thames, M. H., \& Phelps, G. (2008). Content knowledge for teaching: what makes it special? Journal of Teacher Education, 59(5), 389-407.

Blanton, M. L., \& Kaput, J. J. (2005). Characterizing a Classroom Practice That Promotes Algebraic Reasoning. Journal for Research in Mathematics Education, 36(5), 412-443.

Brasil. Base Nacional Comum Curricular - BNCC, Brasília: Ministério da Educação, versão aprovada pelo CNE, novembro de 2017. http://basenacionalcomum.mec.gov.br/wpcontent/uploads/2018/02/bncc-20dez-site

Boavida, A. M. (2008). Raciocinar para aprender e aprender a raciocinar. Educação e Matemática, 100, 1.

Canavarro, A. P. (2009). O pensamento algébrico na aprendizagem da Matemática nos primeiros anos. Quadrante. 16(2), 81-118.

Carrillo, J., Climent, N., Contreras, L. C., \& Muñoz-Catalán, M. C. (2013). Determining Specialized Knowledge for Mathematics Teaching. In B. Ubuz, C. Haser, \& M. A. Mariotti (Eds.), Proceedings VIII Congress of the European Society for Research in Mathematics Education (CERME 8) (pp. 2985-2994). Antalya: Middle East Technical University.

Clandinin, D. J., \& Connelly, F. M. (2011). Pesquisa Narrativa: Experiência e História em Pesquisa Qualitativa. 2ed. Uberlândia: EDUFU.

D’Ambrosio, B. S., \& Lopes, C. E. (2014). Trajetórias de educadoras matemáticas. (Coleção Insubordinação Criativa). Campinas: Mercado de Letras.

Fiorentini, D. (2019). Pesquisar práticas colaborativas ou pesquisar colaborativamente? In: M. C. Borba \& J. L. Araújo (Orgs.), Pesquisa Qualitativa em Educação Matemática, 6 a . Edição (pp. 53-85). Belo Horizonte: Editora Autêntica.

Fiorentini, D. (Org.). (2003). Formação de professores de matemática: explorando novos caminhos com outros olhares. São Paulo: Mercado das Letras. 
Fiorentini, D., \& Crecci, V. (2013). Desenvolvimento Profissional Docente: um termo guarda-chuva ou um novo sentido à formação? Revista Brasileira de Pesquisa sobre Formação Docente, 05(8), 11-23.

Fiorentini, D., Passos, C. L., \& Lima, R. C. L. (2016). Mapeamento da pesquisa acadêmica brasileira sobre o professor que ensina matemática: período 2001 - 2012. Campinas: FE/Unicamp.

Garcia, C. M. (1999). Formação de professores: para uma mudança educativa. Tradução: Isabel Narciso. Lisboa: Porto Editora.

Imbernón, F. (2010). Formação continuada de professores. Porto Alegre: Artmed.

Kaput, J., \& Blanton, M. (2005). Algebrafying the elementary mathematics experience. Part I: Transforming Task Structure. Proceedings of the ICMI-Algebra Conference. Melbourne: Australia.

Nóvoa, A. (2008). Os professores e a sua formação. Lisboa: Dom Quixote.

Radford, L. (2006). Algebraic thinking and the generalization of patterns: A semiotic perspective. In: S. Alatorre, J. L. Cortina, M. Sáiz \& A. Méndez (Eds.), Proceedings of the 28th annual meeting of the North American Chapter of the International Group for the Psychology of Mathematics Education (pp. 2-21). Mérida: Universidad Pedagógica Nacional.

Ribeiro, M. (2017). Conhecimento Interpretativo para ensinar Matemática e História da (Educação) Matemática: contributos para a Formação. Educação \& Linguagem, 20(1), 47-72.

Rodrigues, R. V. R., Cyrino, M. C. C. T., \& Oliveira, H. M. (2018). Comunicação no Ensino Exploratório: visão profissional de futuros professores de Matemática. Bolema, 32 (62), 967-989. DOI: https://doi.org/10.1590/1980-4415v32n62a11.

Trivilin, L. R., \& Ribeiro, A. J. (2015). Conhecimento Matemático para o Ensino de Diferentes Significados do Sinal de Igualdade: um estudo desenvolvido com professores dos Anos Iniciais do Ensino Fundamental. Bolema, 29(51), 38-59.

DOI: https://doi.org/10.1590/1980-4415v29n51a03.

Shulman, L. S. (1986). Those who understand: knowledge growth in teaching. Educational Researcher, 15(2), 4-14.

Smith, M. S., \& Stein, M. K. (2013). Five practices for orchestrating productive mathematics discussion. Virginia: NCTM.

Stacey, K. (1989). Finding and using patterns in linear generalizing problems. Educational Studies in Mathematics, 20, 147-164.

Vale. I. (2012). As tarefas de padrões na aula de Matemática: um desafio para professores e alunos. Interacções (Campo Grande), 20, 181-207.

Vale, I., \& Pimentel, T. (2013). O pensamento algébrico e a descoberta de padrões na formação de professores. Da Investigação às Práticas: Estudos de Natureza Educacional, 3(1), 98-124. 
DOI: $10.20396 /$ zet.v29i00.8661731

Van de Walle, J. A. V. (2009). Matemática no Ensino Fundamental: formação de professores e aplicação em sala de aula. 6a ed. (Tradução: Paulo Henrique Colonese). Porto Alegre: Artmed.

Zeichner, K. M. (2010). Repensando as conexões entre a formação na universidade e as experiências de campo na formação de professores em faculdades e universidade. Educação, 35(3), 479-504. 